\title{
Formation of Surface Depression during Continuous Casting of High-Al TRIP Steel
}

\author{
Heng Cui ${ }^{1, *}$, Kaitian Zhang ${ }^{2}$, Zheng Wang ${ }^{1}$, Bin Chen ${ }^{3}$, Baisong Liu ${ }^{3}$, Jing Qing ${ }^{4}$ and \\ Zhijun Li ${ }^{4}$ \\ 1 Collaborative Innovation Center of Steel Technology, University of Science and Technology Beijing, \\ Beijing 100083, China; wangzheng410@163.com \\ 2 Engineering Research Institute, University of Science and Technology Beijing, Beijing 100083, China; \\ zhangkaitianbk@163.com \\ 3 Shougang Technology Research Center, Shougang Corporation, Beijing 100043, China; \\ ustbchenbin@163.com (B.C.); baisongliu@163.com (B.L.) \\ 4 Beijing Shougang Co. Ltd., Beijing 100043, China; qingjing@sgqg.com (J.Q.); lizhijun@sgqg.com (Z.L.) \\ * Correspondence: cuiheng@ustb.edu.cn; Tel.: +86-136-7123-9796
}

Received: 31 December 2018; Accepted: 5 February 2019; Published: 9 February 2019

\begin{abstract}
High aluminum transformation-induced plasticity (TRIP) steels offer a unique combination of high tensile strength and ductility, high impact energy absorption and good formability. The surface of the slab is prone to depressions and longitudinal cracks during continuous casting due to the high Al content in steels. Surface depressions of the $1.35 \mathrm{wt} . \%$ Al-TRIP steel slab in a steel works were investigated by scanning electronic microscopy (SEM) and mold fluxes with different $\mathrm{Al}_{2} \mathrm{O}_{3} / \mathrm{SiO}_{2}$ ratios were researched by thermodynamic calculations and high-temperature static balance experiments. The results show that some micro-cracks were distributed along the grain boundary in the surface depression of the slab. Inclusions containing $\mathrm{K}$ and $\mathrm{Na}$, which were probably from mold flux, were found in the depression samples. Meanwhile, the components of reactive mold flux showed significant variation in their chemical composition during the continuous casting process of the Al-TRIP steel. A large number of depressions and irregular oscillation marks on the Al-TRIP steel slab surface were generated due to serious deterioration in the physical properties of the mold flux. Since the TRIP steel is a typical hypo-peritectic steel, the overly large thermal contraction and volume contraction during initial solidification is the intrinsic cause of surface depression. The change of mold flux properties during casting aggravates the formation of depressions.
\end{abstract}

Keywords: Al-TRIP steel; surface depression; cracks; non-metallic inclusion; mold flux; reactivity

\section{Introduction}

As automotive lightweighting and safety requirements increase, steels for automotive structural parts are required to have both high strength and ductility. Transformation-induced plasticity (TRIP) steels offer a unique combination of high tensile strength and ductility, high impact energy absorption and good formability [1,2]. Due to the poor wettability properties of silicon-alloyed TRIP steels during hot dip galvanizing, replacing all or part of the silicon with aluminum has been considered. The main advantage of aluminum-alloyed TRIP steels is that they do not form surface oxides, which improves their coating quality and galvanizing properties [3,4].

However, the high Al content in steel can easily lead to deterioration of the surface quality of continuous casting slabs. At present, the $\mathrm{Al}$ content of industrial aluminum-alloyed TRIP steel is generally $0.5-2 \mathrm{wt} . \%$. The surface of the slab is prone to depressions and longitudinal cracks during continuous casting $[5,6]$. 
The depression formation during the continuous casting process is mainly determined by the chemical composition of steel grades [7-9]. Steels with 0.1 and $0.15 \mathrm{wt} . \% \mathrm{C}$ tend to experience higher contraction forces, which build immediately upon initial solidification. This is the reason for the formation of surface depressions, as well as the higher sensitivity to the formation of longitudinal surface cracks [7]. Meanwhile, the addition of aluminum to TRIP steel causes the reaction between [Al] in molten steel and $\left(\mathrm{SiO}_{2}\right)$ in conventional lime-silica-based mold fluxes, resulting in many problems such as the variation of chemical composition, the instability of viscosity and the deterioration of other thermophysical properties of mold flux. These variations have been reported as the principal reasons for some problems during the continuous casting of high-Al steels such as breakout, uneven heat transfer across mold flux, inadequate lubrication and the poor surface quality of as-cast slabs [5,10-12].

In this present work, the metallographic samples at surface depressions of the high-Al TRIP slab were analyzed by scanning electron microscopy equipped with an energy dispersion spectrum (SEM/EDS), and the industrial mold flux was investigated by thermodynamic calculations and high-temperature static balance experiments. Furthermore, the formation of depressions and cracks was discussed from the two aspects of the chemical composition of the steel grade and the reactivity of the mold flux.

\section{Experimental Materials and Methods}

The $1.35 \mathrm{wt} . \%$ Al-TRIP steel used in this present work is produced by the 210t BOF-LF-RH-CC process at Shougang Qianan steel works. The main chemical composition of the Al-TRIP steel slab from the steel works is shown in Table 1. The trial was carried out at one heat with a two-strand continuous slab caster, and the slab section was $1400 \mathrm{~mm} \times 230 \mathrm{~mm}$ with a casting speed of $0.9 \mathrm{~m} / \mathrm{min}$. The superheating of liquid steel within the tundish was controlled within the range of $20-35^{\circ} \mathrm{C}$.

Table 1. Main chemical compositions of Al-transformation-induced plasticity (TRIP) steel (wt.\%).

\begin{tabular}{ccccccc}
\hline $\mathbf{C}$ & $\mathbf{S i}$ & $\mathbf{M n}$ & $\mathbf{P}$ & $\mathbf{S}$ & Alt & $\mathbf{N}$ \\
\hline 0.16 & 0.16 & 1.49 & 0.008 & 0.001 & 1.35 & 0.0016 \\
\hline
\end{tabular}

A large amount of surface depression and irregular oscillation marks were found on the whole inner arc surface except within $100 \mathrm{~mm}$ from the narrow sides of the slab, which was the third slab of the \#1 strand of the sequence, as shown in Figure 1. Samples were respectively cut with the size of $15 \times 15 \times 20 \mathrm{~mm}^{3}$ from the surface depression and the normal surface of the near side and center positions of the slab width on the inner arc slab. For morphological observation, after immerging the material in acetone with ultrasonic oscillation to wash away the surface oil, the samples were subjected to cold acid pickling by dilute hydrochloric acid to remove mill scales. After this the depression morphologies were observed by SEM. For the non-metallic inclusion observation, grinding and polishing was performed on the surface of normal samples, and the thickness direction of both normal samples and depression samples, as well as the type, number and size of non-metallic inclusions of the samples' surface and subsurface (200 $\mu \mathrm{m}$ deep from slab surface), were observed by SEM/EDS. Two hundred and fifty grams of steel was added in a zirconia crucible (inner diameter $=45 \mathrm{~mm}$, outer diameter $=50 \mathrm{~mm}$, height $=75 \mathrm{~mm}$ ), which was put in the constant temperature zone of an Si-Mo high-temperature furnace. Before heating, argon was piped into the closed furnace for $1 \mathrm{~h}$ with a flow rate of $51 / \mathrm{min}$ to eliminate internal air, preventing the oxidation of steel. The steel was then heated to $1550{ }^{\circ} \mathrm{C}$ by $10^{\circ} \mathrm{C} / \mathrm{min}$ and the temperature maintained after the steel melted completely. Sixty grams of pre-melted mold flux was added on the surface of the molten steel, and heat preservation continued for $3 \mathrm{~h}$ until the reaction tended to equilibrium. Finally, the crucible was removed, and after cooling, crushing, and grinding, the mold flux chemical compositions were analyzed by X-ray fluorescence (XRF). In addition, viscosity $\left(1300^{\circ} \mathrm{C}\right)$ was calculated by FactSage software (Thermfact/CRCT, Montreal, Canada and GTT-Technologies, Aachen, Germany) according to the chemical composition before and after the reaction of mold slag and steel. 


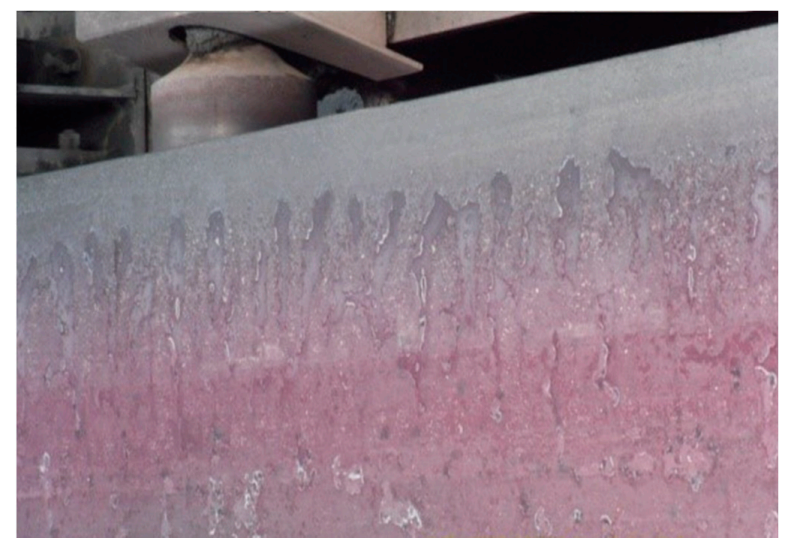

Figure 1. Photograph of surface depressions of the 1.35 wt.\% Al-TRIP steel slab.

\section{Results}

\subsection{Metallographic Analysis}

Figure 2 shows the typical morphology of micro-cracks on the depression samples observed by SEM. The crack length ranged from a few hundred microns to several millimeters and the gap width was tens of microns. The cracks were mainly star cracks along grain boundaries.

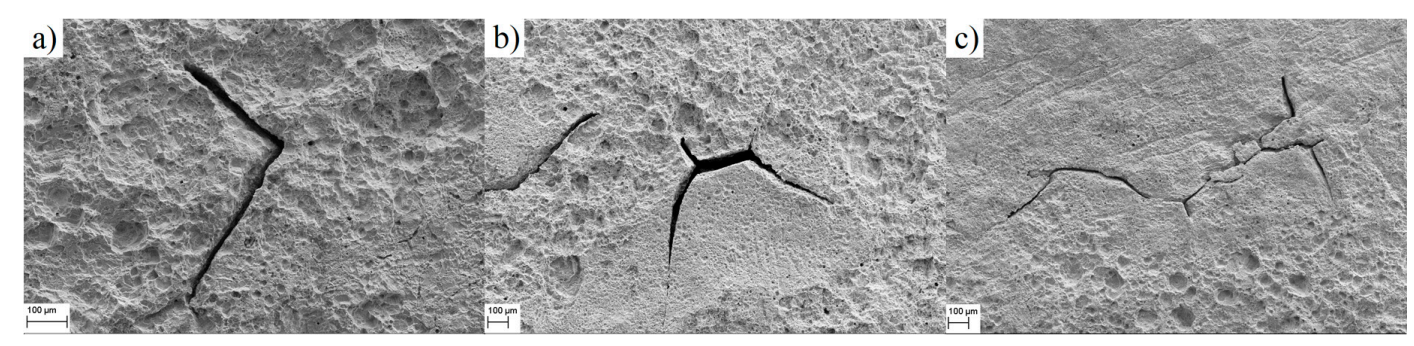

Figure 2. Different morphologies of star cracks on depression samples.

Figure 3 shows the statistic of the inclusion $(\geq 10 \mu \mathrm{m})$ comparison between normal samples and depression samples. Block $\mathrm{Al}_{2} \mathrm{O}_{3}$ inclusions were found on both normal and depression samples. A small amount of cluster $\mathrm{Al}_{2} \mathrm{O}_{3}$ was also found on normal samples, while inclusions containing $\mathrm{K}$ or $\mathrm{Na}$ were only found on depression samples. Moreover, whether on normal or depression samples, the number of inclusions near the side of the slab was more than that in the center of the slab.

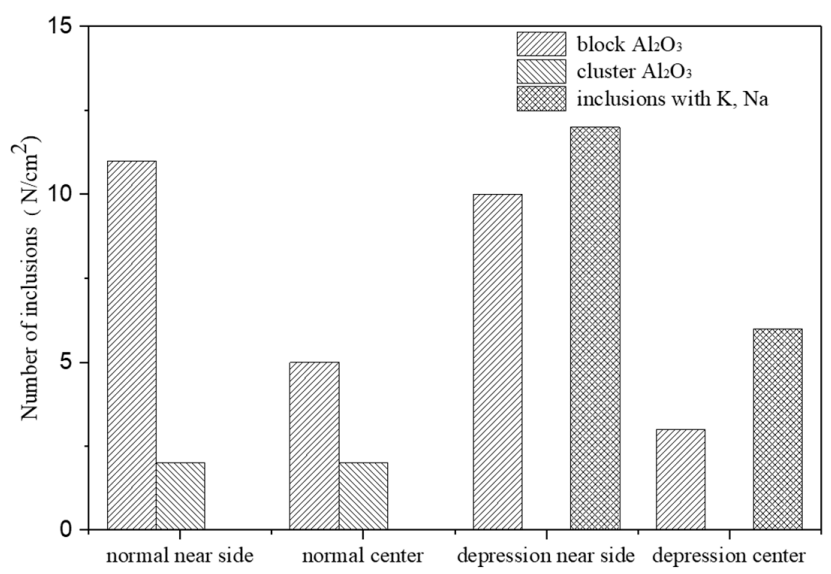

Figure 3. Distribution of inclusions in slab surface and subsurface. 
Figure 4 shows typical inclusions in different positions. Table 2 shows the chemical composition of the inclusions. According to Figure 4 and Table 2, the inclusions in normal samples were mainly block (Figure 4a) and cluster (Figure $4 \mathrm{~b}$ ) $\mathrm{Al}_{2} \mathrm{O}_{3}$; the inclusions in depression samples were mainly $\mathrm{Al}_{2} \mathrm{O}_{3}$ (Figure 4c) and inclusions with the composition of $\mathrm{Na}$ and $\mathrm{K}$ (Figure $4 \mathrm{~d}, \mathrm{e}$ ); the inclusion with the composition of $\mathrm{K}$ was found in the surface cracks of depression samples, as shown in Figure $4 \mathrm{f}$. The $\mathrm{Na}$ and $\mathrm{K}$ elements in the inclusions were generally considered to be derived from the mold slag. As the inclusions in Figure $4 \mathrm{~d}$, f contained more than $40 \mathrm{wt}$ \% Fe, the inclusions may have come from the mixture of mold slag and iron particles, which are probably attributed to argon bubbles scattering the iron particles over the meniscus [13]. Since the observed samples were from the surface of the slab, it was considered that the inclusions in Figure $4 \mathrm{~d}$,f may have resulted from the mold slag entrapping or pressing into the initial solidifying shell.
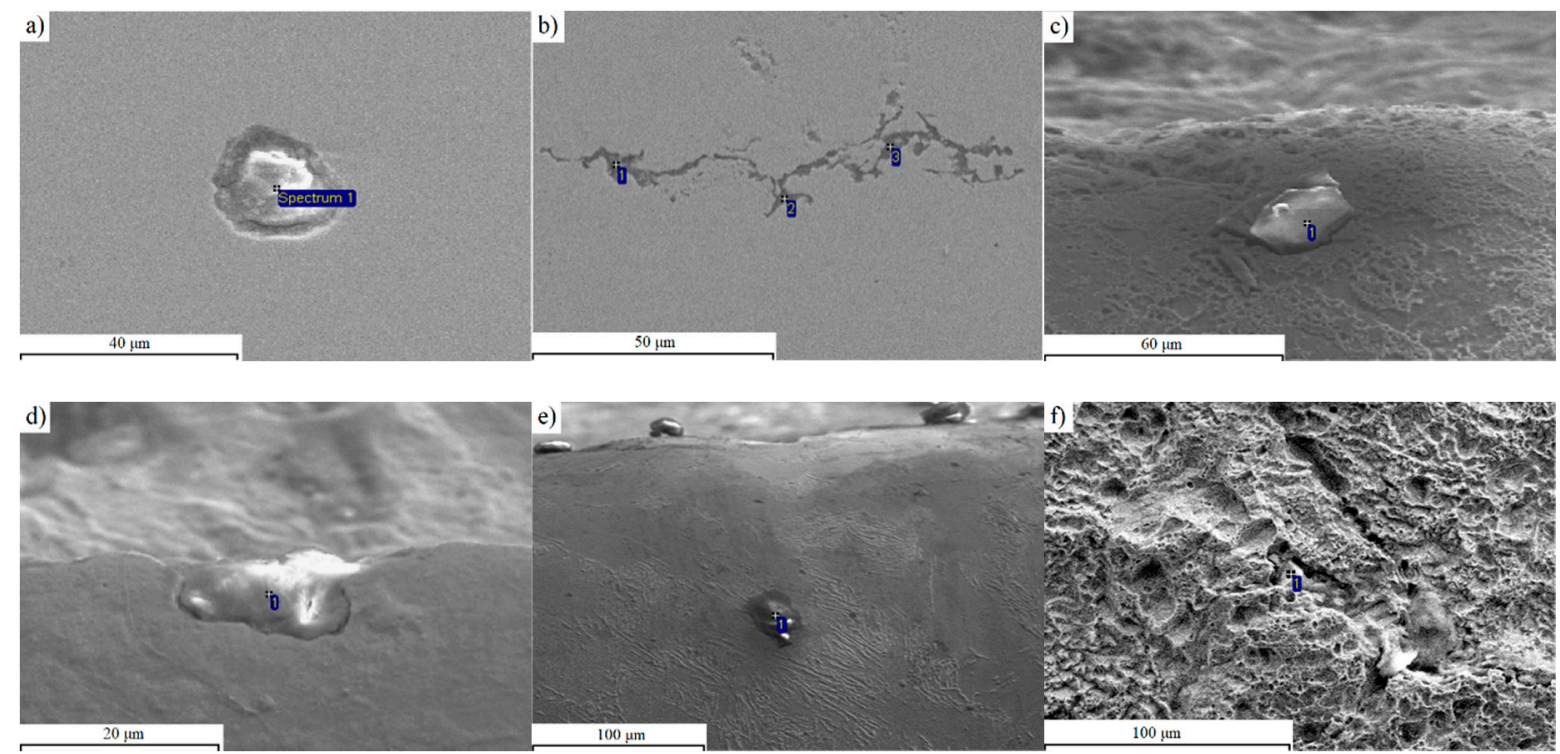

Figure 4. Morphology of non-metallic inclusions. (a,b) normal surface; (c-f) depression surface.

Table 2. Chemical compositions of the inclusions (a-f) (wt.\%).

\begin{tabular}{ccccccccccccc}
\hline Samples & $\mathbf{O}$ & $\mathbf{N a}$ & $\mathbf{M g}$ & $\mathbf{A l}$ & $\mathbf{S i}$ & $\mathbf{M n}$ & $\mathbf{P}$ & $\mathbf{S}$ & $\mathbf{K}$ & $\mathbf{C a}$ & $\mathbf{T i}$ & $\mathbf{F e}$ \\
\hline a & 38.19 & - & - & 57.21 & - & - & - & - & - & - & - & 4.60 \\
b-1 & 55.90 & - & 1.90 & 42.21 & - & - & - & - & - & - & - & - \\
b-2 & 51.09 & - & 4.30 & 42.55 & - & 2.07 & - & - & - & - & - & - \\
b-3 & 55.25 & - & 5.93 & 38.82 & - & - & - & - & - & - & - & - \\
c & 62.14 & - & - & 37.31 & - & - & - & - & - & - & - & 0.55 \\
d & 43.26 & 2.51 & 0.64 & 0.53 & 1.30 & - & 0.42 & 5.39 & 0.57 & 2.49 & - & 42.89 \\
e & 7.56 & 4.55 & 0.64 & 1.76 & 0.59 & 1.60 & - & 0.57 & 0.62 & 0.56 & - & 81.56 \\
f & 36.43 & - & - & 5.26 & 0.99 & 0.54 & - & 1.15 & 0.48 & - & 0.79 & 54.37 \\
\hline
\end{tabular}

\subsection{Reactivity of Mold Fluxes for Al-TRIP Steel}

The $\mathrm{Al}_{2} \mathrm{O}_{3}$ accumulation in the mold slag containing $\mathrm{SiO}_{2}$ is unlikely to be avoided under the presence of $\mathrm{Al}$ in the steel by the following chemical reaction [12]:

$$
\begin{gathered}
{[\mathrm{Al}]+\frac{3}{4}\left(\mathrm{SiO}_{2}\right)=\frac{3}{4}[\mathrm{Si}]+\frac{1}{2}\left(\mathrm{Al}_{2} \mathrm{O}_{3}\right)} \\
\Delta \mathrm{G}^{\Theta}{ }_{1}=-164550+26.775 T \\
\Delta \mathrm{G}_{1}=\Delta \mathrm{G}^{\Theta}{ }_{1}+R T \ln \frac{\left(a_{\mathrm{Al}_{2} \mathrm{O}_{3}}\right)^{1 / 2}\left(a_{\mathrm{Si}}\right)^{3 / 4}}{\left(a_{\mathrm{SiO}_{2}}\right)^{3 / 4}\left(a_{\mathrm{Al}}\right)} .
\end{gathered}
$$


The activities of $\mathrm{Al}$ and $\mathrm{Si}(\alpha \mathrm{Al}$ and $\alpha \mathrm{Si})$ in liquid steel at $1550{ }^{\circ} \mathrm{C}$ were calculated by FactSage software and Wanger Model with $\omega[\mathrm{i}]=1 \%$ solution as a standard. Due to the low content of other elements in liquid steel, the temperature has less influence on the activity interaction coefficient, and $1873 \mathrm{~K}$ was chosen for calculation. The results are as follows: $f_{\mathrm{Al}}=1.230, f_{\mathrm{Si}}=1.345, \alpha_{[\mathrm{Al}]}=1.660$, $\alpha_{[\mathrm{Si}]}=0.215$. The activities of $\mathrm{Al}_{2} \mathrm{O}_{3}$ and $\mathrm{SiO}_{2}$ in the mold flux were calculated using the FToxid database in FactSage software. The results are as follows: $\alpha_{(\mathrm{SiO} 2)}=5.25 \times 10^{-2}, \alpha_{(\mathrm{Al2O})}=5.50 \times 10^{-5}$. Finally, it was calculated that $\Delta \mathrm{G}_{1}=181.7 \mathrm{~kJ} / \mathrm{mol}$ at $1550{ }^{\circ} \mathrm{C}$.

A special mold flux for peritectic steel was used in the industrial test of the TRIP steel. The compositions of the industrial slag before and after the steel/slag reaction are shown in Table 3 . This was investigated by high-temperature static balance experiments. The findings reveal that the industrial mold flux has a great tendency to react with liquid steel. After the equilibrium reaction, the $\mathrm{w}\left(\mathrm{SiO}_{2}\right)$ in slag decreased from $40.35 \%$ to $28.90 \%$; $\mathrm{w}\left(\mathrm{Al}_{2} \mathrm{O}_{3}\right)$ increased from $1.07 \%$ to $12.58 \%$. This is similar to that reported in document [6]; after casting high-Al TRIP steel for $24 \mathrm{~min}$, the mold flux composition became almost constant, the $\mathrm{SiO}_{2}$ content was stable between $13 \mathrm{wt} . \%$ and $15 \mathrm{wt} . \%$ from $35.10 \mathrm{wt} . \%$ and the $\mathrm{Al}_{2} \mathrm{O}_{3}$ content was $40 \mathrm{wt} . \%$ from $1.50 \mathrm{wt} . \%$. As a result, the properties of mold flux deteriorated; for example, there was a $79.74 \%$ increase in viscosity (from $0.232 \mathrm{~Pa} \cdot \mathrm{s}$ to $0.417 \mathrm{~Pa} \cdot \mathrm{s}$ ), as shown in Table 3. Varying viscosity led to various casting problems, including sticking of the mold flux to copper mold, non-uniform heat transfer across the mold flux, reduced consumption of mold flux, reduced lubrication and poor as-cast slab surface quality, etc. $[5,10]$.

Table 3. Compositions of industrial slag before and after steel/slag interfacial reaction (wt.\%).

\begin{tabular}{|c|c|c|c|c|c|c|c|c|c|c|c|}
\hline Slag Sample & $\mathrm{CaO}$ & $\mathrm{SiO}_{2}$ & $\mathrm{Al}_{2} \mathrm{O}_{3}$ & $\mathrm{CaF}_{2}$ & $\mathrm{MnO}$ & $\mathrm{BaO}$ & $\mathrm{Na}_{2} \mathrm{O}$ & $\mathrm{Fe}_{2} \mathrm{O}_{3}$ & $\mathrm{MgO}$ & $\mathrm{CaO} / \mathrm{SiO}_{2}$ & $\begin{array}{c}\text { Viscosity } \\
\text { (Pa.s) }\end{array}$ \\
\hline Before reaction & 36.30 & 40.35 & 1.07 & 13.66 & 0.21 & 0.50 & 6.64 & 0.58 & 0.68 & 0.90 & 0.232 \\
\hline After reaction & 39.60 & 28.90 & 12.58 & 12.73 & 1.57 & 0.59 & 1.52 & 1.33 & 1.17 & 1.37 & 0.417 \\
\hline
\end{tabular}

Non-reactive mold flux is expected to suppress reaction (1) by reducing $\alpha\left(\mathrm{SiO}_{2}\right)$ and increasing

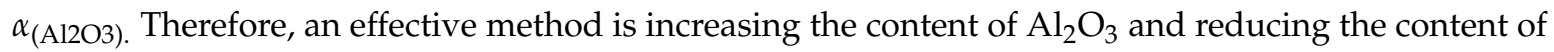
$\mathrm{SiO}_{2}$ in mold flux. The different ratios of $\mathrm{Al}_{2} \mathrm{O}_{3} / \mathrm{SiO}_{2}$ mold flux samples were analyzed for their thermodynamics based on the industrial mold flux. The main components of slags are shown in Table 4 . When the $\mathrm{Al}_{2} \mathrm{O}_{3} / \mathrm{SiO}_{2}$ ratio increased, $\alpha_{(\mathrm{Al} 2 \mathrm{O} 3)}$ increased while $\alpha_{(\mathrm{SiO} 2)}$ decreased and $\Delta \mathrm{G}$ tended to 0 , which means a significant reduction in the driving force of reaction (1). Specifically, the $\mathrm{Al}_{2} \mathrm{O}_{3} / \mathrm{SiO}_{2}$ ratio increased from 0.16 to 2.08 , and there was a $48.5 \%$ reduction of $\Delta \mathrm{G}$. In addition, $\Delta \mathrm{G}$ changed sharply at the beginning while it tended to be stable until the $\mathrm{Al}_{2} \mathrm{O}_{3} / \mathrm{SiO}_{2}$ ratio reached 1.18; after that, increasing $\mathrm{Al}_{2} \mathrm{O}_{3} / \mathrm{SiO}_{2}$ had less effect on the reactivity.

Table 4. The mold flux for high aluminum steel with different $\mathrm{Al}_{2} \mathrm{O}_{3} / \mathrm{SiO}_{2}$ ratios.

\begin{tabular}{ccccccccc}
\hline Samples & $\mathbf{C a O}$ & $\mathbf{S i O}_{\mathbf{2}}$ & $\mathbf{A l}_{\mathbf{2}} \mathbf{O}_{\mathbf{3}}$ & $\mathbf{A l}_{\mathbf{2}} \mathbf{O}_{\mathbf{3}} / \mathbf{S i O}_{\mathbf{2}}$ & $\mathbf{a}\left(\mathrm{SiO}_{\mathbf{2}}\right)$ & $\mathbf{a}\left(\mathrm{Al}_{\mathbf{2}} \mathbf{O}_{\mathbf{3}}\right)$ & $\begin{array}{c}\Delta \mathbf{G} \\
(\mathbf{k J} / \mathbf{m o l})\end{array}$ & $\begin{array}{c}\text { Viscosity } \\
(\mathbf{P a} \cdot \mathbf{s})\end{array}$ \\
\hline $\mathrm{A}-1$ & 30 & 32 & 5 & 0.16 & $3.50 \times 10^{-2}$ & $1.10 \times 10^{-3}$ & -154.4 & 0.293 \\
$\mathrm{~A}-2$ & 30 & 27 & 10 & 0.37 & $2.24 \times 10^{-3}$ & $2.41 \times 10^{-2}$ & -99.7 & 0.277 \\
$\mathrm{~A}-3$ & 30 & 22 & 15 & 0.68 & $4.36 \times 10^{-4}$ & $1.55 \times 10^{-2}$ & -84.5 & 0.258 \\
$\mathrm{~A}-4$ & 30 & 17 & 20 & 1.18 & $2.76 \times 10^{-4}$ & $1.40 \times 10^{-2}$ & -80.1 & 0.238 \\
$\mathrm{~A}-5$ & 30 & 12 & 25 & 2.08 & $2.16 \times 10^{-4}$ & $1.06 \times 10^{-2}$ & -79.4 & 0.219 \\
\hline
\end{tabular}

All mold flux samples in Table 4 were tested for slag/steel reaction by the equilibrium experiments. The compositions and viscosities of slag samples with different $\mathrm{Al}_{2} \mathrm{O}_{3} / \mathrm{SiO}_{2}$ ratios after reaction were analyzed, as shown in Table 5 . Increasing the $\mathrm{Al}_{2} \mathrm{O}_{3} / \mathrm{SiO}_{2}$ ratio can not only reduce the consumption of $\mathrm{SiO}_{2}$ in mold slag, but it can also decrease the increment of $\mathrm{Al}_{2} \mathrm{O}_{3}$ significantly compared with that before the reaction. The above findings indicate that the properties of mold flux for high $\mathrm{Al}$ steel could 
be improved by increasing the $\mathrm{Al}_{2} \mathrm{O}_{3} / \mathrm{SiO}_{2}$ ratio. It is possible to inhibit slag property deterioration due to reaction (1) during the continuous casting process.

Table 5. Compositions of mold slag with different $\mathrm{Al}_{2} \mathrm{O}_{3} / \mathrm{SiO}_{2}$ ratios after steel/slag reaction (wt.\%).

\begin{tabular}{cccccccc}
\hline Sample & $\mathbf{C a O}$ & $\mathbf{S i O}_{\mathbf{2}}$ & $\mathbf{A l}_{\mathbf{2}} \mathbf{O}_{\mathbf{3}}$ & $\boldsymbol{\Delta} \mathbf{S i O}_{\mathbf{2}}(\mathbf{\%})$ & $\boldsymbol{\Delta A l}_{\mathbf{2}} \mathbf{O}_{\mathbf{3}}(\mathbf{\%})$ & $\mathbf{C a O} / \mathrm{SiO}_{\mathbf{2}}$ & $\mathbf{V i s c o s i t y}(\mathbf{P a} \cdot \mathbf{s})$ \\
\hline $\mathrm{A}-1$ & 34.25 & 20.14 & 17.53 & -37.50 & 250.51 & 1.70 & 0.298 \\
$\mathrm{~A}-2$ & 34.49 & 18.41 & 23.93 & -31.82 & 139.29 & 1.87 & 0.286 \\
$\mathrm{~A}-3$ & 31.94 & 15.18 & 25.42 & -31.00 & 69.49 & 2.10 & 0.306 \\
A-4 & 33.17 & 12.00 & 28.37 & -29.41 & 41.85 & 2.76 & 0.245 \\
A-5 & 32.33 & 8.58 & 34.00 & -29.17 & 36.02 & 3.77 & 0.278 \\
\hline
\end{tabular}

Figure 5 shows the viscosities of mold fluxes with different $\mathrm{Al}_{2} \mathrm{O}_{3} / \mathrm{SiO}_{2}$ ratios calculated by FactSage software. With the increase of the $\mathrm{Al}_{2} \mathrm{O}_{3} / \mathrm{SiO}_{2}$ ratio, the viscosity reduced for the samples before the reaction, and there was a significant reduction of viscosity variation $(0.24-0.30 \mathrm{~Pa} \cdot \mathrm{s})$ for the samples after the reaction compared with the industrial slag sample. Therefore, it is possible to reduce the mold flux reactivity significantly as long as the $\mathrm{Al}_{2} \mathrm{O}_{3} / \mathrm{SiO}_{2}$ ratio can be adjusted to 1.18. In addition, some acidic oxides and fluxes which could adjust the basicity and crystallization properties such as $\mathrm{B}_{2} \mathrm{O}_{3}$ and $\mathrm{LiO}_{2}$, should be added to slag because of the low content of $\mathrm{SiO}_{2}[14,15]$.

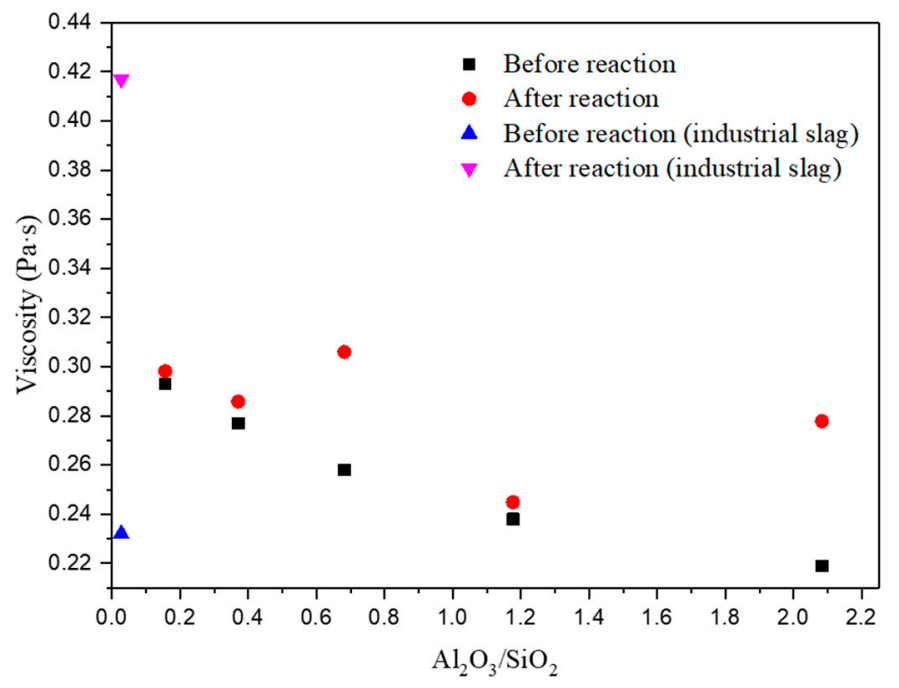

Figure 5. Comparison of the viscosity of the samples between before and after reaction.

\section{Discussion}

The thermal contraction of the solidifying shell in the meniscus region of a continuous casting mold is of great importance to the surface and subsurface quality of the cast products $[7,16]$. It is well known that peritectic steels with an equivalent carbon content $\left(C_{P}\right)$ between 0.09 and 0.17 (the characteristic points $C_{\mathrm{A}}$ and $C_{\mathrm{B}}$ in the binary Fe-C system) are more prone to cracks and depressions than others. The binary $\mathrm{Fe}-\mathrm{C}$ equilibrium phase diagram and the pseudo-binary $\mathrm{Fe}-\mathrm{C}$ phase diagram of the $1.35 \mathrm{wt} . \%$ Al-TRIP steel were calculated by the commercial thermodynamic software ThermoCalc 2018b (database: TCFE8). Figure 6 shows the high-temperature ranges of the phase diagrams. The calculated chemical composition of the $1.35 \mathrm{wt} . \%$ Al-TRIP steel is shown in Table 1. 


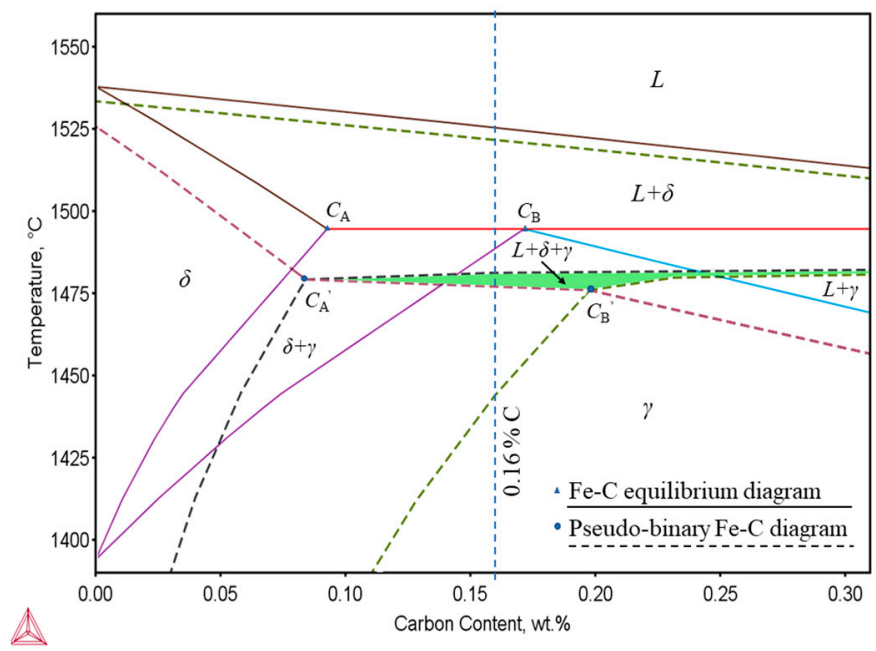

Figure 6. Fe-C equilibrium diagram and pseudo-binary Fe-C diagram of the 1.35 wt.\% Al-TRIP steel.

According to the $\mathrm{Fe}-\mathrm{C}$ phase diagram, $C_{\mathrm{A}}$ and $C_{\mathrm{B}}$ were 0.09 and $0.17 \mathrm{C}$ wt. $\%$ at the peritectic phase transformation temperature of $1494.63{ }^{\circ} \mathrm{C}$, respectively. The $1.35 \mathrm{wt} . \%$ Al-TRIP steel contains high $\mathrm{Mn}$ and $\mathrm{Al}$ elements, of which $\mathrm{Mn}$ is an austenite former and $\mathrm{Al}$ is a ferrite former. It can be seen that the presence of $\mathrm{Mn}$ and $\mathrm{Al}$ led to the formation of a peritectic ternary region $(L+\delta+\gamma)$. In the phase diagram, $C_{\mathrm{A}}$ moved to $0.08 \mathrm{wt} . \%$ in the lower left at temperature of $1479.14{ }^{\circ} \mathrm{C}$, while $C_{\mathrm{B}}$ moved to $0.20 \mathrm{wt} . \%$ in the lower right at temperature of $1475.92{ }^{\circ} \mathrm{C}$. Compared with the $\mathrm{Fe}-\mathrm{C}$ equilibrium phase diagram, the pseudo-binary Fe-C phase diagram has larger $L+\delta$ and $\delta+\gamma$ two-phase regions. The $1.35 \mathrm{wt} . \%$ Al-TRIP steel $(0.16 \mathrm{wt} . \% \mathrm{C})$ is a typical hypo-peritectic steel, and its solidification sequence was $L \rightarrow L+\delta \rightarrow L+\delta+\gamma \rightarrow \delta+\gamma \rightarrow \gamma$ above $1400^{\circ} \mathrm{C}$, as shown in Figure 6. The liquid-solid phase transition of the TRIP steel was from 1521.80 to $1477.17^{\circ} \mathrm{C}$, while that of the Fe-C alloy was from 1525.41 to $1494.63{ }^{\circ} \mathrm{C}$ when the $\mathrm{C}$ content was $0.16 \mathrm{wt} . \%$. Thus, the TRIP steel had larger thermal contraction due to the liquid-solid phase transition. Furthermore, the peritectic phase transition $L$ $+\delta \rightarrow \gamma$ caused larger volume contraction during the liquid TRIP steel solidification, because the $\delta$ (body-centered cubic) transit to $\gamma$ (face-centered cubic) was from 1481.32 to $1444.17^{\circ} \mathrm{C}$, while that of the $\mathrm{Fe}-\mathrm{C}$ alloy was from 1494.63 to $1488.81^{\circ} \mathrm{C}$. As with the addition of $\mathrm{Al}$ and $\mathrm{Mn}$ in the $\mathrm{Fe}-\mathrm{C}$ binary alloy (hypo-peritectic steel), the temperature range of the $L$ to $\gamma$ phase transition increased from 36.60 to $77.63{ }^{\circ} \mathrm{C}$, and the solidifying shell of the TRIP steel was subjected to larger thermal and volumetric contraction forces than the normal hypo-peritectic steel during initial solidification. The contraction forces can reach maximum within a few seconds of solidification [7]. Therefore, a transverse air gap is generated between the solidifying shell and the mold, which prevents heat transfer. When the shell is pulled downward, it is moved close to the mold again by the heat flow and static pressure of the molten steel, thus forming a transverse depression. In order to reduce the risk of formation of surface depression, the $C$ content of $1.35 \mathrm{wt} . \%$ Al-TRIP should move right to $C_{B}{ }^{\prime}$ to reduce the region from the $L$ phase to $\gamma$ phase under the condition of satisfying the steel grade design.

Depression formation further results in uneven shell growth and coarse grains in the region of surface depression because the speed of solidification and cooling in depression parts is slower than that in other parts. Under the action of thermal stress and ferrostatic pressure, the stress at the depression is concentrated. When the stress exceeds the critical strength of the shell, cracks are generated at the weak grain boundary of the depression. As shown in Figure 2, depression was often accompanied by micro-cracks, which were cracked along the coarse grains in the depression surface or subsurface. The more serious depressions there are on the surface of the solidifying shell, the greater is the risk of crack formation. If there is too much additional external mechanical stress acting on the shell, the development of the micro-cracks will be further aggravated. 
The two important functions of the mold flux are to lubricate the moving slab and to adjust the heat transfer from the solidifying shell to the mold wall. The stability of heat transfer in the mold is closely related to the uniform and stable inflow of mold slag during the continuous casting process. Because of the high requirement of heat transfer uniformity during the solidification and cooling process of peritectic steels, it is suitable to reduce the heat conduction of the mold flux and slow cool the slab under the condition of guaranteeing the thickness of the shell. For high-aluminum peritectic steels, special attention should also be paid to the reactivity of mold flux, as mentioned above.

The special mold flux for peritectic steel, which belongs to reactive mold flux, was used for this industrial test of the TRIP steel, as shown in Table 3. The slag chemical composition changed greatly during the high Al-TRIP steel continuous casting: $w\left(\mathrm{SiO}_{2}\right)$ decreased by $28.38 \% ; w\left(\mathrm{Al}_{2} \mathrm{O}_{3}\right)$ increased by $1024.55 \%$. These variations caused the serious deterioration of mold flux properties; for example, viscosity increased by $79.74 \%$. The deterioration of mold flux properties during casting has serious effects on the liquid slag layer thickness, the mold slag inflow between the solidifying shell and mold wall and slag rim formation in the mold meniscus. The liquid level fluctuates acutely, resulting in slag entrainment. The heat transfer between the solidifying shell and mold wall becomes inhomogeneous, leading to the shell shrinking more inhomogeneously, and the risk of depression formation is increased. Furthermore, the slag rim aggravates the formation of depressions due to its obstacles to the infiltration of the slag film into the gap between the mold wall and the shell, and may press some slag film into the initial shell with mold oscillation. This is a reason why inclusions containing $\mathrm{K}$ and Na were found in the surface depression, as shown in Figure $4 \mathrm{~d}$,e.

It is possible to reduce the risk of surface depression of high-aluminum TRIP slab according to this present work and the literature using the following measures: (1) increasing the $C$ content of steel, under the condition of satisfying the steel grade design, to reduce thermal and volume contraction during initial solidification; (2) adopting a non-reactive $\mathrm{CaO}-\mathrm{Al}_{2} \mathrm{O}_{3}$-based mold flux with an appropriate melting point and viscosity, improving the mold flux viscosity and melting rate, controlling heat flux in the mold and liquid slag thickness to improve the heat transfer condition of the shell/mold and the homogeneous growth of the shell [5,10-12]; (3) feeding the molten mold flux into the casting mold to enhance the thermal insulation of the meniscus and, hence, the lubrication between the solidifying shell and the copper mold wall [17].

\section{Conclusions}

This research investigated the formation of depressions of $1.35 \mathrm{wt} . \%$ Al-TRIP steel. The following conclusions can be made:

(1) A large number of depressions and irregular oscillation marks were found on the slab surface of $1.35 \% \mathrm{Al}$-TRIP steel during the continuous casting process with reactive mold flux, and micro-cracks were found along the grain boundary on the slab surface and subsurface. Non-metallic inclusions containing $\mathrm{K}$ and $\mathrm{Na}$ were found in the depression surface samples, while the main inclusion in the normal surface sample was that of $\mathrm{Al}_{2} \mathrm{O}_{3}$;

(2) The $1.35 \mathrm{wt} . \%$ Al-TRIP steel is a typical hypo-peritectic steel; $C_{\mathrm{A}}$ moved to $0.08 \mathrm{wt} . \%$ in the lower left at a temperature of $1479.14{ }^{\circ} \mathrm{C}$, while $C_{\mathrm{B}}$ moved to $0.20 \mathrm{wt} . \%$ in the lower right at a temperature of $1475.92{ }^{\circ} \mathrm{C}$ in the pseudo-binary $\mathrm{Fe}-\mathrm{C}$ diagram. The overly large thermal contraction and volume contraction caused by the peritectic reaction during initial solidification is the intrinsic cause of surface depression;

(3) The change of mold flux properties during casting aggravates the formation of depressions due to the chemical reaction between the mold flux and the alloying element $\mathrm{Al}$ in Al-TRIP steel. Increasing the $\mathrm{Al}_{2} \mathrm{O}_{3} / \mathrm{SiO}_{2}$ ratio of the mold flux could obviously reduce the reactivity of slag; however, there is no significant change in viscosity. As the $\mathrm{Al}_{2} \mathrm{O}_{3} / \mathrm{SiO}_{2}$ ratio increased from 0.16 to $2.08, \Delta \mathrm{G}$ began to change rapidly and tended to stabilize when the ratio exceeded 1.18 . 
Author Contributions: Conceptualization, H.C.; Data curation, H.C.; Investigation, Z.W., B.L., J.Q. and Z.L.; Resources, B.C.; Writing-original draft, K.Z.; Writing-review and editing, H.C.

Funding: This research was funded by the National Natural Science Foundation of China (No. U1860106) and the China Scholarship Council (No. 201806465050).

Conflicts of Interest: The authors declare no conflict of interest.

\section{References}

1. Fonstein, N.; Pottore, N.; Lalam, S.H.; Bhattacharya, D. Phase transformation behavior during continuous cooling and isothermal holding of aluminum and silicon bearing TRIP steels. In Proceedings of the Materials Science and Technology, Chicago, IL, USA, 9-12 November 2003.

2. Tuling, A.; Banerjee, J.R.; Mintz, B. Influence of peritectic phase transformation on hot ductility of high aluminium TRIP steels containing Nb. Mater. Sci. Tech. 2011, 27, 1724-1731. [CrossRef]

3. Bellhouse, E.M.; Mertens, A.I.M.; McDermid, J.R. Development of the surface of TRIP steels prior to hot-dip galvanizing. Mat. Sci. Eng. A 2007, 436, 147-156. [CrossRef]

4. Bhattacharyya, T.; Singh, S.B.; Bhattacharyya, S.; Ray, R.K.; Bleck, W.; Bhattacharjee, D. An assessment on coatability of trans formation induced plasticity (TRIP)-aided steel. Surf. Coat. Tech. 2013, 235, 226-234. [CrossRef]

5. Shi, C.B.; Seo, M.D.; Cho, J.W.; Kim, S.H. Crystallization Characteristics of CaO- $\mathrm{Al}_{2} \mathrm{O}_{3}$-Based Mold Flux and Their Effects on In-Mold Performance during High-Aluminum TRIP Steels Continuous Casting. Metall. Mater. Trans. B 2014, 45B, 1081-1097. [CrossRef]

6. Ji, C.X.; Cui, Y.; Zeng, Z.; Tian, Z.H.; Zhao, C.L.; Zhu, G.S. Continuous casting of high-Al steel in Shougang Jingtang steel works. J. Iron Steel Res. Int. 2015, 22, 53-56. [CrossRef]

7. Bernhard, C.; Xia, G. Influence of alloying elements on the thermal contraction of peritectic steels during initial solidification. Ironmak. Steelmak. 2006, 33, 52-56. [CrossRef]

8. Pierer, R.; Bernhard, C. High temperature behavior during solidification of peritectic steels under continuous casting conditions. In Proceedings of the Materials Science and Technology, Cincinnati, OH, USA, 15-19 October 2006.

9. Presoly, P.; Pierer, R.; Bernhard, C. Identification of defect prone peritectic steel grades by analyzing high-temperature phase transformations. Metall. Mater. Trans. A 2013, 44A, 5377-5388. [CrossRef]

10. Wang, W.L.; Blazek, K.; Cramb, A. A study of the crystallization behavior of a new mold flux used in the casting of transformation-induced-plasticity steels. Metall. Mater. Trans. B 2008, 39B, 66-74. [CrossRef]

11. Cho, J.W.; Blazek, K.; Frazee, M.; Yin, H.B.; Park, J.H.; Moon, S.W. Assessment of CaO- $\mathrm{Al}_{2} \mathrm{O}_{3}$ based mold flux system for high aluminum TRIP casting. ISIJ Int. 2013, 53, 62-70. [CrossRef]

12. Liu, Q.; Wen, G.; Li, J.; Fu, X.; Tang, P.; Li, W. Development of mould fluxes based on lime-alumina slag system for casting high aluminium TRIP steel. Ironmak. Steelmak. 2014, 41, 292-297. [CrossRef]

13. Cui, H.; Wu, H.J.; Yue, F.; Wu, W.S.; Wang, M.; Bao, Y.P.; Chen, B.; Ji, C.X. Surface defects of cold-rolled Ti-IF steel sheets due to non-metallic inclusions. J. Iron Steel Res. Int. 2011, 18, 335-340.

14. Solek, K.; Korolczuk-Hejnak, M.; Slezak, W. Viscosity measurements for modeling of continuous steel casting. Arch. Metall. Mater. 2012, 57, 333-338.

15. Lu, B.X.; Chen, K.; Wang, W.L.; Jiang, B.B. Effects of $\mathrm{Li}_{2} \mathrm{O}$ and $\mathrm{Na}_{2} \mathrm{O}$ on the crystallization behavior of lime-alumina-based mold flux for casting high-Al steels. Metall. Mater. Trans. B 2014, 45B, 1496-1509. [CrossRef]

16. Thomas, B.G.; Storkman, W.R. Mathematical models of continuous slab casting to optimize mold taper. In Proceedings of the Modeling and Control of Casting and Welding Processes, Warrendale, PA, USA, 17-22 April 1988.

17. Cho, J.W.; Yoo, S.; Park, M.S.; Park, J.K.; Moon, K.H. Improvement of castability and surface quality of continuously cast TWIP slabs by molten mold flux feeding technology. Metall. Mater. Trans. B 2017, 48B, 187-196. [CrossRef]

(C) 2019 by the authors. Licensee MDPI, Basel, Switzerland. This article is an open access article distributed under the terms and conditions of the Creative Commons Attribution (CC BY) license (http:/ / creativecommons.org/licenses/by/4.0/). 